\title{
The green-agile supplier selection problem for the medical devices: a hybrid fuzzy decision-making approach
}

\author{
Fatemeh Alamroshan ${ }^{1} \cdot$ Mahyar La'li $^{2} \cdot$ Mohsen Yahyaei ${ }^{3,4}$ \\ Received: 23 February 2021 / Accepted: 31 May 2021 / Published online: 30 August 2021 \\ (C) The Author(s), under exclusive licence to Springer-Verlag GmbH Germany, part of Springer Nature 2021
}

\begin{abstract}
The supplier selection problem (SSP) is known as one of the major issues in the supply chain management area. In this field, the literature shows that the combination of green and agile indicators has been ignored by researchers. Hence, this research attempts to study the SSP considering green and agile aspects, simultaneously. To do this, an efficient hybrid fuzzy decision-making approach is developed based on the Fuzzy Decision-Making Trial and Evaluation Laboratory (FDEMATEL), Fuzzy Best-Worst Method (FBWM), Fuzzy Analytic Network Process (FANP), and Fuzzy Vlse Kriterijumsk Optimizacija Kompromisno Resenje (FVIKOR) methods. Then, to show the efficiency and application of the proposed approach, a case study in the medical devices industry is investigated. After determining the main indicators and alternatives, the interrelationships between indicators are identified employing FDEMATEL. Then, the weights of indicators are calculated using integrated FBWM-FANP. Finally, the potential suppliers are ranked applying FVIKOR. Based on the obtained results, price and greenness are the more important aspects and also material costs, environmental performance evaluation, manufacture flexibility, service level, and system reliability are the most important criteria for the green-agile supplier selection problem in the medical devices industry. Since all of the consistency ratios are less than 0.1 , the reliability of the results is proved. On the other side, the results of conducting sensitivity analysis show that by changing the defuzzification methods, there is no significant change in the obtained results that demonstrates the validity of the proposed approach. Eventually, based on the obtained results, suppliers \#1 and \#5 are the best suppliers for the considered company.
\end{abstract}

Keywords Green supplier selection · Agile supplier selection · Hybrid decision-making $\cdot$ Medical devices $\cdot$ DEMATEL $\cdot$ VIKOR

\section{Introduction}

\section{Responsible Editor: Eyup Dogan}

Mohsen Yahyaei

mohsen.yahyaei@polymtl.ca

Fatemeh Alamroshan

alamroshan@gmail.com

Mahyar La'li

S.mahyarlali@gmail.com

1 Department of Industrial Engineering, Babol Noshirvani University of Technology, Babol, Iran

2 Department of Industrial Engineering, Mazandaran University of Science and Technology, Babol, Iran

3 Département de mathématiques et de génie industriel, Polytechnique Montréal, Montréal, Québec, Canada

4 Centre interuniversitaire de recherche sur les réseaux d'entreprise, la logistique et le transport (CIRRELT), Universite de Montreal, Montréal, Québec, Canada
In today's competitive market space, the importance of supply chain (SC) management has received more and more attention. Nowadays, the managers of firms know that without having an efficient plan for their SC, they are doomed to remove from the market (Nayeri et al. 2020, 2021; Sazvar et al. 2021). In this domain, one of the major branches of SC management is the supplier selection problem (SSP) (Fallahpour et al. 2018, 2021). In general, the SSP aims at ranking the potential suppliers based on the desired criteria for providing the needed raw materials. Statistical reports showed that about $65-75 \%$ of the capital cost is invested in purchasing raw materials ( $\mathrm{Li}$ et al. 2020; Mehrbakhsh and Ghezavati 2020). Nowadays, due to the increasing the current world, we have to change our approach to solve real-life issues (such as environmental issues) (Hocine et al. 2020). In the traditional SSP, only financial indicators have been considered for ranking the potential suppliers. However, increasing 
concerns about the environmental pollutants and also global warming led to a shift in the researchers' attention to the green SSP (GSSP). Overall, the GSSP tries to select the best suppliers based on economic and environmental indicators (Fallahpour et al. 2019; Wei et al. 2021).

One of the significant features in the field of SC management is agility. In general, agile SC seeks to efficiently and effectively respond to increasingly dynamic and volatile markets (Alimardani et al. 2013). In other definition, agility means using market knowledge to exploit beneficial chances in a volatile marketplace (Ciccullo et al. 2018). In the agile SC area, aligning the companies with their supply partners is advised that results in improving the efficiency of their operations. On the other side, working together leads to reach the required levels of agility in the whole of SC (Alimardani et al. 2013). Hence, one of the most important factors of agility is the supply partner selection process that is a vital issue for surviving in nowadays' drastically competitive environment. This critical issue has been rarely addressed by researchers in the SSP area.

Based on the World Health Organization (WHO), medical devices are known as an important industry in the healthcare system. Without medical devices, common medical procedures would not be possible. The recent pandemic (COVID19) shows the critical role of medical devices in ensuring the quality of life across the world. Nowadays, it is estimated that there are about two million various types of medical devices on the world market, categorized into more than 7000 generic device groups. On the other side, there are many suppliers that provide raw materials to manufacture different types of medical devices. Hence, it seems necessary to study SSP for these goods that have been rarely addressed in the previous papers especially considering agile criteria.

In general, decision-making is regarded as the cognitive process to select an alternative among several potential alternatives according to some indicators (Simon 1977). There are several decision-making methods, e.g., support vector machine, artificial neural network, autoregressive integrated moving average, AHP, DEMATEL, and TOPSIS, which are widely used in different fields such as supply chain management and financial markets (Aslan et al. 2017; Altan and Karasu 2019; Sunay et al. 2020). One of the important applications of the decision-making methods is related to the SSP. In the related literature, researchers applied several methods to investigate the green or agile supplier selection. In this regard, for example, some studies employed the DEMATEL method to identify the interrelationship among the green or agile aspects (for example, see Yazdani et al. (2017) and Li et al. (2020)); some papers applied pair-wise comparison-based methods (e.g., AHP, ANP and BWM) to calculate weights of the aspects and criteria (for example, see Hasan et al. (2008), Wu et al. (2009) Beikkhakhian et al. (2015), Graham et al. (2015), and Rouyendegh et al. (2020)). Also, there are many studies that used different methods such as TOPSIS, VIKOR, and DEA to rank the potential suppliers (for example, see Alimardani et al. (2013), Beikkhakhian et al. (2015), Rouyendegh et al. (2020), and Chen et al. (2018)). However, there is a lack of academic research that simultaneously tries to study the green and agile SSP, identify interrelationships among the aspects/criteria, calculate weights of the aspects/criteria according to their interrelationships, and rank the potential suppliers. On the other side, when the interrelationships among the aspects/criteria are determined, usually the ANP method is applied to measure the weights of the aspects/criteria. Nonetheless, by increasing the number of the aspects/criteria, the number of pair-wise comparison matrices of the mentioned method is increased, drastically. This drawback leads to an increase in the computing burden and a decrease in the reliability of results. On the other side, due to the imprecision/uncertainty of the business environment, decision-makers prefer to use the tools to cope with this uncertainty. In this regard, the fuzzy theory is one of the strongest and most common approaches. Hence, this study investigates the research problem under the fuzzy environment.

Therefore, owing to the above-mentioned points, this paper attempts to propose a hybrid fuzzy decision-making approach to investigate the green-agile supplier selection problem (GASSP) for the medical devices industry in which the interrelationships among the aspects/criteria are identified, the weights of the aspects/criteria are calculated, and the potential suppliers are ranked. To do this, at the outset, the main aspects and criteria of the GASSP are extracted based on the experts' opinions literature and. Then, interrelationships among the indicators are obtained using the Fuzzy Decision-Making Trial and Evaluation Laboratory (FDEMATEL). In the next step, in order to reduce the number of pair-wise comparisons that lead to a decrease in the computing burden and an increase in the reliability of results, the integrated Fuzzy BestWorst Method (FBWM)-Fuzzy Analytic Network Process (FANP) method is employed to calculate the weights of the indicators. In the last stage, the Fuzzy Vlse Kriterijumsk Optimizacija Kompromisno Resenje (FVIKOR) method is applied to rank the potential suppliers. The main advantages of the proposed approach over the available approaches are as follows:

a. The proposed hybrid method considers the interrelationships among indicators using the FDEMATEL method.

b. The proposed hybrid method leads to decreasing the number of pair-wise comparisons and also increasing the reliability of the results by combining the FBWM and FANP methods.

c. The proposed hybrid method maximizes the group utility and minimizing individual effects by employing FVIKOR to rank the potential suppliers. 
d. The proposed hybrid method investigates the problem under the fuzzy environment.

On the other side, the main advantages of this research over the previous related papers are as follows:

I. This study simultaneously considers the green and agile indicators in the SSP. In the other words, to the best of our knowledge, this is the first study that investigates the green-agile supplier selection problem.

II. This research considers the interrelationships between different aspects and criteria in the green and agile SSP.

III. This paper develops an efficient hybrid approach that concurrently benefits the advantages of different decision-making methods.

IV. This study selects the medical devices industry as a case study due to the importance of this industry, especially during the COVID-19 pandemic.

The current study is structured as follows. The literature is reviewed in the second section. The third section provides the methodology of this research. The case study and the obtained results are presented in the fourth section. Theoretical and managerial implications are given in the fifth section. Eventually, conclusions and future suggestions are presented in the sixth section.

\section{Literature review}

In recent years, due to the importance of the supply chain and decision-making problems, many works have conducted in this area especially under the fuzzy environment (for example, see De 2018, 2020, 2021; De and Sana 2018; De and Mahata 2019; De and Mahata 2020, 2021; Bhattacharya and De 2021; Bhattacharya et al. 2021). In this section, we review the most important previous papers related to green or agile supplier selection problems. This section is divided into three parts: (i) reviewing the green supplier selection problem, (ii) reviewing the agile supplier selection problem (ASSP), and (iii) research gaps and contributions.

\section{Green supplier selection}

In the two last decades, several works have been conducted in the field of the GSSP due to increasing concerns about environmental damages of SC management. In this regard, Graham et al. (2015) tried to develop a new decision-making method to study the GSSP for the electronic machinery manufacturing industry. In the mentioned study, the authors combined AHP, entropy, and TOPSIS methods and results showed the efficiency of the proposed approach. Yazdani et al. (2017) combined DEMATEL, QFD, and COPRAS methods to investigate the
GSSP. To show the efficiency of the proposed approach, they implemented the proposed hybrid method in the manufacturing industry as a case study. Mousakhani et al. (2017) developed a hybrid approach based on the TOPSIS method and hamming distance measure to investigate the GSSP for the battery industry under the interval type-2 fuzzy environment. Banaeian et al. (2018) investigated the GSSP for the agricultural food industry and compared different methods (VIKOR, GRA, and TOPSIS) in the fuzzy environment. Chen et al. (2018) tried to develop a decision-making method based on the neutrosophic linguistic TOPSIS method for the GSSP problem. Gao et al. (2020) studied the GSSP by developed a hybrid method based on PLPR, MCGDM, and consensus decision-making approaches. The authors selected a case study in the electronics manufacturing industry to show the application of the proposed method. Javad et al. (2020) investigated the SSP considering green indicators for Khouzestan Steel Company in Iran. The authors developed a method by combining the BWM and fuzzy TOPSIS. Rouyendegh et al. (2020) studied the GSSP for a company in Ankara by developing an intuitionistic fuzzy TOPSIS. The obtained results showed that the offered approach had the high performance to select the best supplier due to indicators of the GSSP. Pinar et al. (2021) developed the q-Rung Orthopair Fuzzy TOPSIS approach to select the best suppliers considering green criteria for a Turkish company. They compared the results of the developed method with the traditional TOPSIS and showed that their approach obtained more stable results. Mabrouk (2021) aimed at investigating the SSP considering green criteria. In the mentioned research, seven categories and 58 attributes are considered and then the fuzzy Delphi method was employed to filter and rate unneeded factors according to their relevance. Foroozesh et al. (2021) tried to introduce an efficient decisionmaking method based on Monte Carlo simulation under intervalvalued fuzzy and stochastic environments. To show the efficiency of the offered method, the authors compared the results of their method with other existing methods. Haeri and Rezaei (2019) investigated the green supplier selection problem by developing a hybrid decision-making model based on the best-worst method and fuzzy grey cognitive maps. Then, to show the effectiveness and applicability of the developed approach, they examined a real case study. Kilic and Yalcin (2020) proposed a multi-phase approach based on the TOPSIS and fuzzy goal programming methods to investigate the green supplier selection problem under the fuzzy environment. They selected a case study in the air filter industry to demonstrate the application of the proposed framework. Çalık (2021) developed a hybrid method based on the Pythagorean fuzzy AHP and the Pythagorean fuzzy TOPSIS to investigated the GSSP under the fuzzy environment in Industry 4.0 era. To show the performance of the proposed model, the author implemented the developed framework at a case study in an agricultural tool and machinery company. Bera et al. (2021) studied the GSSP by developing a hybrid approach based on the FAHP method and the Taguchi 
loss function. Their approach assessed the loss of supplier's performance due to the relevant factors and identifies the best supplier to perform effectively for the organization.

\section{Agile supplier selection}

Although there are several papers in the field of agile SC management, limited studies have been conducted in the agile supplier selection area. For example, Hasan et al. (2008) studied the ASSP for an Indian manufacturing firm by developing a method based on ANP and DEA approaches. Wu and Barnes (2009) conducted a study to examine the agile supplier selection problem. The authors developed a decision-making framework that includes the feedback from the focal industry so that it can help to improve the process continuously. Wu et al. (2009) combined a mathematical model and the ANP method to investigate partner selection in the agile supply chain. Luo et al. (2009) worked on the ASSP regarding informationprocessing problems. The authors applied an artificial neural network to assess the alternatives based on both qualitative and quantitative data. They selected an electrical appliances industry in China as a case study to show the efficiency and application of the proposed approach. Wu and Barnes (2009) designed a two-phase framework based on a multi-objective mathematical model and the ANP method for investigating the agile partner selection problem in the supply chain. $\mathrm{Wu}$ and Barnes (2014) investigated the partner selection problem in the agile supply chain under the fuzzy environment. The authors considered an electrical company in China and employed the artificial neural network method to select the best partners. Alimardani et al. (2013) studied the ASSP in the automobile industry. The authors developed a hybrid approach based on the SWARA and VIKOR methods. Beikkhakhian et al. (2015) developed an approach based on the interpretive structural modeling, AHP, and TOPSIS methods to study the supplier selection problem considering agile criteria. The authors considered a manufacturing industry to show the application of the proposed approach. Galankashi and Helmi (2016) worked on the ASSP for semiconductor manufacturing industries under the fuzzy environment. The authors applied the AHP method to assess the potential suppliers based on the agile criteria. Li et al. (2020) employed the DEMATEL method to investigate lean and agile supplier selection problem for Chinese textile industries. The authors firstly identified the main criteria of the problem and then determined the most influential criterion using the DEMATEL approach. Goker et al. (2020) designed a novel decision-making framework to investigate the ASSP. They aimed at ranking the suppliers due to agile indicators by introducing a novel distance-based hierarchical intuitionistic decision-making procedure. The authors showed the application of the proposed method by selecting a real case study in the dye industry.

\section{Research gaps and contributions}

The literature shows that the agile SSP especially under the fuzzy environment has been less addressed by previous studies. In this regard, Hasan et al. (2008), Alimardani et al. (2013), Wu and Barnes (2009), and $\mathrm{Li}$ et al. (2020) investigated deterministic agile supplier selection and only Galankashi and Helmi (2016) investigated the agile SSP under the fuzzy environment. However, in today's dynamic market, which is influenced by rapid growth in population and technology, considering agile factors is needed to change frequently in response to rapidly changing business environments. On the other side, due to imprecision/uncertainty, employing fuzzy theory can dramatically improve the decision-making process. On the other hand, it should be noted that considering interrelationships between criteria in the agile supplier selection problem has been less addressed by previous studies (only Li et al. (2020) considered interrelationships in this area). Also, simultaneous consideration of green and agile indicators in the supplier selection problem was ignored by the researchers in the previous studies. Also, the related literature in the field of green or agile supplier selection problem showed that there is a lack of an efficient comprehensive decision-making framework, which is simultaneously capable to identify interrelationships among the indicators, calculate the weights of indicators (according to their interrelationships), and rank the alternatives. Developing such an approach can lead to improve the decision-making process due to its advantages. On the other hand, it can be seen in the literature that there is no paper that investigated the agile or green SSP for medical devices. Nevertheless, medical devices are critical goods that their role has been highlighted more and more during the recent pandemic period. Hence, investigating the SSP problem for these goods seems to be necessary. In this regard, this research aims at investigating the green-agile supplier selection for the medical devices industry. To do this, a hybrid fuzzy decision-making approach is developed. At first, the interrelationships between the main aspects and criteria of the GASSP are identified. Then, in order to increase the reliability of results and decrease cognitive burden, FBWM is used to measure the initial weights of aspects/criteria. Afterward, considering the interrelationships, the final weights of aspects/criteria are measured applying FANP. Finally, the potential suppliers are ranked using the FVIKOR method. According to the above-mentioned points, we have divided the main contributions of this study into two parts as follows:

\section{- The theoretical contributions}

- This is the first study that investigates green-agile supplier selection under the fuzzy environment. As aforementioned, the importance of the green aspect of the supplier selection problem has increased in recent years due to the raising of environmental concerns and establishing some international regulations. 
Therefore, considering the green indicators is much important. On the other side, in today's competitive market and according to the uncertain nature of the business environment, the concept of agility becomes vital in supply chain management. Thus, considering agile indicators is very important in the supplier selection problem. Hence, this paper aims at contributing to this field by investigating the green-agile supplier selection problem.

- This study aims at developing a hybrid fuzzy decisionmaking framework by combining the FDEMATEL, FBW, FANP, and FVIKOR methods to benefit from their advantages, concurrently. The proposed approach has some advantages that can contribute to the related literature. These advantages are as follows: (a) considering the interrelationships between aspects and criteria, (b) decreasing computing burden, (c) increasing the reliability of the results, and (d) minimizing individual effects and maximizing the group utility.

\section{- The practical contributions}

- Due to the high importance of the medical device especially during the recent pandemic (COVID-19), this study considers the medical devices industry as the case study. This research tries to contribute to the supplier selection problem in the medical devices industry by identifying the main green and agile indicators, determining the interrelationships between them, and prioritizing the indicators.

- This paper attempts to give a good perspective to the managers in order to know the main green-agile indicators and select the best suppliers for their company based on these indicators.

- In order to know practical contributions to the literature, this research provides some managerial implications.

\section{Methodology}

This section is dedicated to presenting the methods that are applied in this research. This section is divided into five parts: (i) defining FDEMATEL, (ii) defining FBWM, (iii) defining FANP, (iv) defining FEDAS, and finally (v) describing the proposed hybrid approach.

\section{FDEMATEL}

FDEMATEL is one of the widely used MADM approaches that is employed to determine interrelationships between different indicators. This method includes the following steps:
Step 1: In the outset, data gathering must be performed. In this way, the opinions of experts are collected applying linguistic scales that have been shown in Table 1.

Step 2: In this phase, the decision matrix is formed according to the collected data in the previous step. In general, for $p$ experts and $n$ criteria, we have $p$ fuzzy matrix with $n$ rows and $n$ columns. The final decision matrix is equal to average of the mentioned matrices.

Step 3: In this, the fuzzy decision matrix must be normalized using the following relations (suppose that $\widetilde{a}=$ $(l, m, r)$ represents a triangular fuzzy number).

$\widetilde{a}_{i j}=\sum_{j=1}^{n} \widetilde{Z}_{i j}=\left(\sum_{j=1}^{n} l_{i j}, \sum_{j=1}^{n} m_{i j}, \sum_{j=1}^{n} r_{i j}\right)$ and $r=\max _{1 \leq i \leq n}\left(\sum_{j=1}^{n} r_{i j}\right)$
$\widetilde{X}=\left[\begin{array}{ccc}\widetilde{X}_{11} & \cdots & \widetilde{X}_{1 n} \\ \vdots & \ddots & \vdots \\ \widetilde{X}_{m 1} & \cdots & \widetilde{X}_{m n}\end{array}\right]$ and $\widetilde{X}_{i j}=\frac{\widetilde{Z}_{i j}}{r}=\left(\frac{l_{i j}}{r}, \frac{m_{i j}}{r}, \frac{r_{i j}}{r}\right)$

Step 4: In this step, the total fuzzy matrix is calculated employing the following equations.

$$
\begin{aligned}
& {\left[l_{i j}^{\prime \prime}\right]=X_{l} \times\left(1-X_{l}\right)^{-1}} \\
& {\left[m_{i j}^{\prime \prime}\right]=X_{m} \times\left(1-X_{m}\right)^{-1}} \\
& {\left[r_{i j}^{\prime \prime}\right]=X_{r} \times\left(1-X_{r}\right)^{-1}}
\end{aligned}
$$

Step 5: The causal diagram is created in this phase. $D_{i}$ shows the sum of the elements of each row and $R_{i}$ denotes the sum of the elements of each column. $D$ indicates the degree of influence of the indicator on the other indicators and $R$ indicates degree of effectiveness of the indicator from other indicators. Then, $D+R$ and $D-R$ are calculated for each factor. Vector $D+R$ shows the effectiveness of the desired factor on the system and also vector $D-R$ shows the impact power of each factor. The causal diagram is drawn based on $D+R$ (the horizontal vector) and $D-R$ (the vertical vector).

\section{FBWM}

The best-worst method is one of the decision-making methods proposed by Rezaei (2015) that works based on the pair-wise comparison matrix (PCM). Comparing to other PCM-based methods, this approach has some advantages such as (i) drastically decreasing in the pair-wise comparisons, (ii) 
Table 1 Linguistic variables and the corresponding fuzzy numbers for FDEMATEL (BaykasoğLu et al. 2013)

\begin{tabular}{llllll}
\hline Linguistic terms & No influence (No) & Very low influence (VL) & Low influence (L) & High influence (H) & Very high influence (VH) \\
\hline Fuzzy numbers & $(1,1,1)$ & $(2,3,4)$ & $(4,5,6)$ & $(6,7,8)$ & $(8,9,9)$ \\
\hline
\end{tabular}

dramatically increasing in reliability of the results, and (iii) the capability of combining with other methods (Ecer 2021). For employing the mentioned method in fuzzy environment, Guo and Zhao (2017) introduced the fuzzy BWM. The steps of FBWM has been explained below.

Step 1: Determining the best and the worst criteria.

Step 2: In this phase, the pair-wise comparisons between the best criteria and others, and also the others and the worst criteria must have been performed. To do this, Table 2 can be employed.

Step 3: The optimal weights are calculated in this step. Suppose that $\widetilde{w}_{j}=\left(l_{j}^{w}, m_{j}^{w}, u_{j}^{w}\right)$ shows the vector of weights, $\tilde{a}_{B j}=\left(l_{B j}, m_{B j}, u_{B j}\right)$ denotes the best-toothers vector representing $\widetilde{a}_{j w}=\left(l_{j W}, m_{j W}, u_{j W}\right)$ others-to-worst vector. The following model has been proposed to measure the optimal weights.

$$
\begin{array}{ll}
\min \widetilde{\xi}^{*} & \\
\text { S.t }: & \\
\left|\frac{\left(l_{B}^{w}, m_{B}^{w}, u_{B}^{w}\right)}{\left(l_{j}^{w}, m_{j}^{w}, u_{j}^{w}\right)}-\left(l_{B j}, m_{B j}, u_{B j}\right)\right| \leq\left(k^{*}, k^{*}, k^{*}\right) & \forall j \\
\left|\frac{\left(l_{j}^{w}, m_{j}^{w}, u_{j}^{w}\right)}{\left(l_{W}^{w}, m_{W}^{w}, u_{W}^{w}\right)}-\left(l_{j W}, m_{j W}, u_{j W}\right)\right| \leq\left(k^{*}, k^{*}, k^{*}\right) & \forall j \\
\sum_{j=1}^{n} R\left(\widetilde{w}_{j}\right)=1 & \\
l_{j}^{w} \leq m_{j}^{w} \leq u_{j}^{w} & \forall j \\
l_{j}^{w} \geq 0 & \forall j \\
& \forall j
\end{array}
$$

Also, it should be noted that for $\widetilde{a}=\left(a_{1}, a_{2}, a_{3}\right)$, the graded mean integration representation (GMIR), denoted by $R$ $(\widetilde{a})$, is defined as follows:

$R(\widetilde{a})=\frac{a_{1}+4 a_{2}+a_{3}}{6}$
Step 4: Checking the consistency ratio (CR). To do this, we divide the value of objective function of the model $(7)\left(\widetilde{\xi}^{*}\right)$ by consistency index (CI). The amount of CI is estimated based on comparison of the best and the worst criteria $\left(\widetilde{a}_{B W}\right)$ (see Table 3).

\section{FANP}

ANP is one of the widely used PCM-based MADM methods that calculate the weights of indicators. In contrast with AHP, this approach is network-based and considers the interrelationships between indicators among the decision levels. In fact, without assuming the independence of elements, the ANP goes far beyond the AHP (Mohammadzadeh et al. 2018). In general, some nodes with elements inside them show the clusters and arcs denote the interrelationships among two components (Özdemir et al. 2020). Since the data gathering process usually is with ambiguity and imprecision, the researchers developed the fuzzy ANP method for the fuzzy environment. In this research, to decrease the number of pair-wise comparisons and increasing the reliability of results, at first, we measure the initial weights of the indicators without considering interrelationships applying the FBWM. Afterward, based on the results obtained by the FBWM and also considering interrelationships, final weights of the indicators are measured by the FANP method using the SuperDecision software.

\section{FVIKOR}

VIKOR is one of the widely used decision-making methods that offer compromising solutions and can create stable decision-making performance by replacing the adaptive solution with the primary weight (Opricovic and Tzeng 2004). Adaptive solution theory is a practical solution that is close to the ideal solution, and adaptation means the agreement made by scores. The VIKOR method provides the maximum productivity of the "majority" group and the minimum individual regret of the "opposite" group and the agreed solution can be easily achieved by decision-makers. As the VIKOR method is

Table 2 Linguistic variables and the corresponding fuzzy numbers for FBWM (You et al. 2017)

\begin{tabular}{llllll}
\hline Linguistic terms & Equally important (EI) & Weakly important (WI) & Fairly important (FI) & Very important (VI) & Absolutely important (AI) \\
\hline Fuzzy numbers & $(1,1,1)$ & $(0.6667,1,1.5)$ & $(1.5,2,2.5)$ & $(2.5,3,3.5)$ & $(3.5,4,4.5)$ \\
\hline
\end{tabular}


Table 3 CI for FBWM (You et al. 2017)

\begin{tabular}{lll}
\hline & $\widetilde{a}_{B W}$ & $\mathrm{CI}$ \\
\hline$(\mathrm{AI})$ & $(7 / 2,4,9 / 2)$ & 8.04 \\
$(\mathrm{VI})$ & $(5 / 2,3,7 / 2)$ & 6.69 \\
$(\mathrm{FI})$ & $(3 / 2,2,5 / 2)$ & 5.29 \\
$(\mathrm{WI})$ & $(2 / 3,1,3 / 2)$ & 3.80 \\
$(\mathrm{EI})$ & $(1,1,1)$ & 3.00 \\
\hline
\end{tabular}

not able to model uncertainty, researchers developed the fuzzy VIKOR method that consists of the following steps:

Step 1: Creating a group of decision-makers (experts).

Step 2: Determining the appropriate linguistic variables for scoring alternatives according to the criteria. For this step, Table 4 can be applied.

Step 3: Creating the normal fuzzy decision matrix where $\widetilde{\mathrm{x}}_{\mathrm{ij}}$ is the score of alternative $\mathrm{A}_{\mathrm{i}}$ based on the criteria of $\mathrm{C}_{\mathrm{j}}$.

$\tilde{D}=\left[\begin{array}{cccccc}\tilde{x}_{11} & \tilde{x}_{12} & \cdot & \cdot & \cdot & \tilde{x}_{1 \mathrm{n}} \\ \tilde{x}_{21} & \tilde{x}_{22} & \cdot & \cdot & \cdot & \tilde{x}_{2 \mathrm{n}} \\ \cdot & \cdot & \cdot & \cdot & \cdot & \cdot \\ \cdot & \cdot & \cdot & \cdot & \cdot & \cdot \\ \cdot & \cdot & \cdot & \cdot & \cdot & \cdot \\ \tilde{x} \sim_{\mathrm{m} 1} & \tilde{x}_{\sim_{\mathrm{m} 2}} & \cdot & \cdot & \cdot & \tilde{x} \sim_{\mathrm{mn}}\end{array}\right]$

Step 4: Defuzzification of the decision matrix employing Eq. 10:

$x_{i j}=\frac{\left[\left(U x_{i j}-L x_{i j}\right)+\left(M x_{i j}-L x_{i j}\right)\right]}{3}+L x_{i j}$

Step 5: Determining the best value (BV) and the worst value (WV).

$f_{i}^{-}=\min _{i} x_{i j}, f_{i}^{*}=\max _{i} x_{i j}$

Step 6: Calculating the value of $s_{i}$ and $R_{i}$.

$S_{i}=\sum_{j=1}^{n} w_{j}\left(f_{j}^{*}-x_{i j}\right) /\left(f_{j}^{*}-f_{j}^{-}\right)$

Table 4 Linguistic variables of FVIKOR (Musani and Jemain 2015)
$R_{i}=\max _{j}\left[w_{j}\left(f_{j}^{*}-x_{i j}\right) /\left(f_{j}^{*}-f_{j}^{-}\right)\right]$

Step 7: Determine $s^{-}, s^{*}, R^{-}, R^{*}$, and $Q_{i}$.

$S^{*}=\min _{i} S_{i}, \quad S^{-}=\max _{i} S_{i}$

$\widetilde{R}^{-}=\max _{i} \widetilde{R}_{i}, \quad R^{*}=\min _{i} R_{i}$

$Q_{j}=v\left(S_{i}-S^{*}\right) /\left(S^{-}-S^{*}\right)+(1-v)\left(R_{i}-R^{*}\right) /\left(R^{-}-R^{*}\right)$

where $v$ means the weight of the group's maximum productivity strategy.

Step 8: Prioritizing the alternatives based on $Q_{i}$.

Step 9: Determining the agreed solution

Determining the agreed solution: suppose the following two conditions are acceptable. Afterward, the agreed solution is determined as the only desirable solution.

Condition 1. Acceptable advantage:

$Q\left(a^{\prime \prime}\right)-Q\left(a^{\prime}\right) \geq D Q$

$D Q=\frac{1}{m-1}(D Q=0.25$ if $m \leq 4)$

Condition 2. Acceptable stability in decision-making: $a^{\prime}$ should be ranked with use of $S$ and $R$.

If one of the conditions above is not met, then a set of agreed solutions is suggested. That includes the following:

If condition 1 is not met, then $a^{\prime}$ has not the agreed advantage and the agreed solutions of $a^{\prime}, a^{\prime \prime}, \ldots, a^{(m)}$ are equal. If condition 2 is not met, stability in decision-making is imperfect. $a^{\prime}$ has the agreed advantage and $a^{\prime}$ is equal to $a^{\prime \prime}$.

Step 10: Selecting the best solution (minimum $Q_{i}$ ).

\section{Hybrid method}

In this section, we explain the steps of the proposed hybrid method. The main importance of developing such a comprehensive approach is its multiple-capability such as (a) identifying interrelationships among indicators, (b) measuring weights of the indicators, (c) reducing the

\begin{tabular}{llllllll}
\hline Linguistic terms & Very poor (VP) & Poor $(\mathrm{P}))$ & Medium Poor $(\mathrm{MP})$ & Fair $(\mathrm{F})$ & Medium good $(\mathrm{MG})$ & Good $(\mathrm{G})$ & Very good $(\mathrm{VG})$ \\
\hline Fuzzy numbers & $(0.0,0.0,1.0)$ & $(0.6667,1,1.5)$ & $(1.0,3.0,5.0)$ & $(3.0,5.0,7.0)$ & $(5.0,7.0,9.0)$ & $(7.0,9.0,10.0)$ & $(9.0,10.0,10.0)$ \\
\hline
\end{tabular}


Fig. 1 The framework of the proposed approach $\underline{\text { Stage } 1}$

Identifying the main aspects, criteria and alternative of the research problem $\underline{\text { Stage } 2}$

Determining the interrelationships between aspects and criteria using FDEMATEL

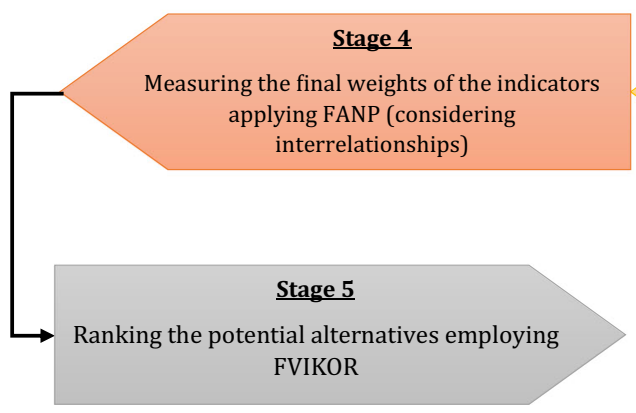

\section{$\underline{\text { Stage } 3}$}

Calculating the initial weights of the indicators using FBWM (without considering interrelationships) computing burden, (d) increasing the reliability of results, (e) ranking the suppliers considering the group utility, and (f) investigating the problem under the fuzzy environment, simultaneously. Although the previous papers in the field of the green-agile supplier selection problem developed several decision-making frameworks, none of them developed a method that simultaneously has the aforementioned capabilities. In this paper, at first, the main aspects, criteria and alternatives are determined based on the literature and experts. In the next step, the FDEMATEL approach is employed to determine the interrelationships between indicators. Then, in order to increase the reliability of the results and decrease the cognitive burden, the integrated FBWM-FANP is applied to calculate weights of aspects and criteria. Eventually, we use the FVIKOR method to rank the potential alternatives based on determined indicators. This method is a useful tool for multi-criteria decision-making, especially when decision-makers cannot easily express their preferences in decision-making due to the existence of conflicting indicators. The compromise solution obtained in the FVIKOR method will be agreed upon by the decision-makers. Under this strategy, the group utility is maximized and the individual effects are minimized. The proposed hybrid

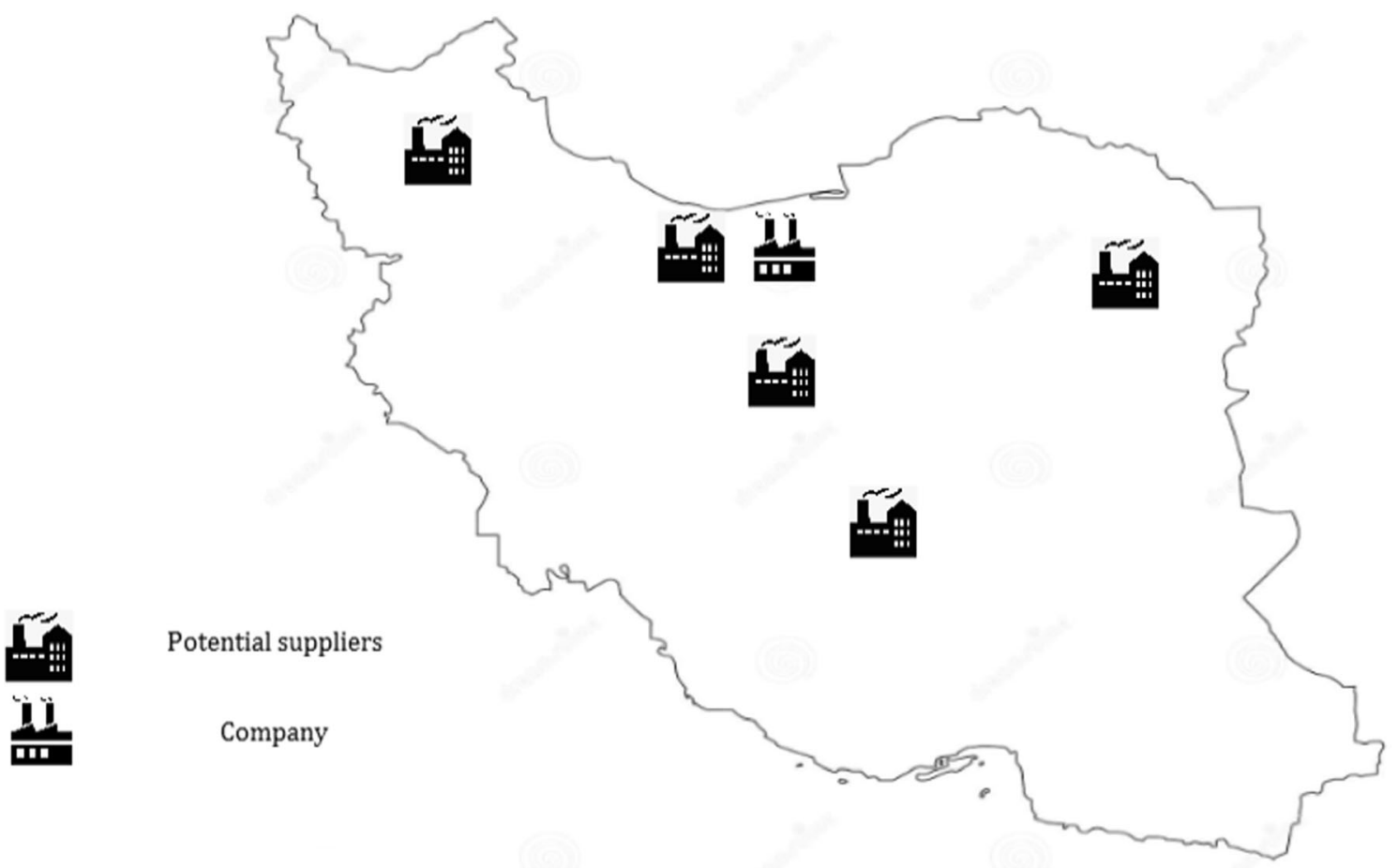

Fig. 2 The location of the company and potential suppliers 


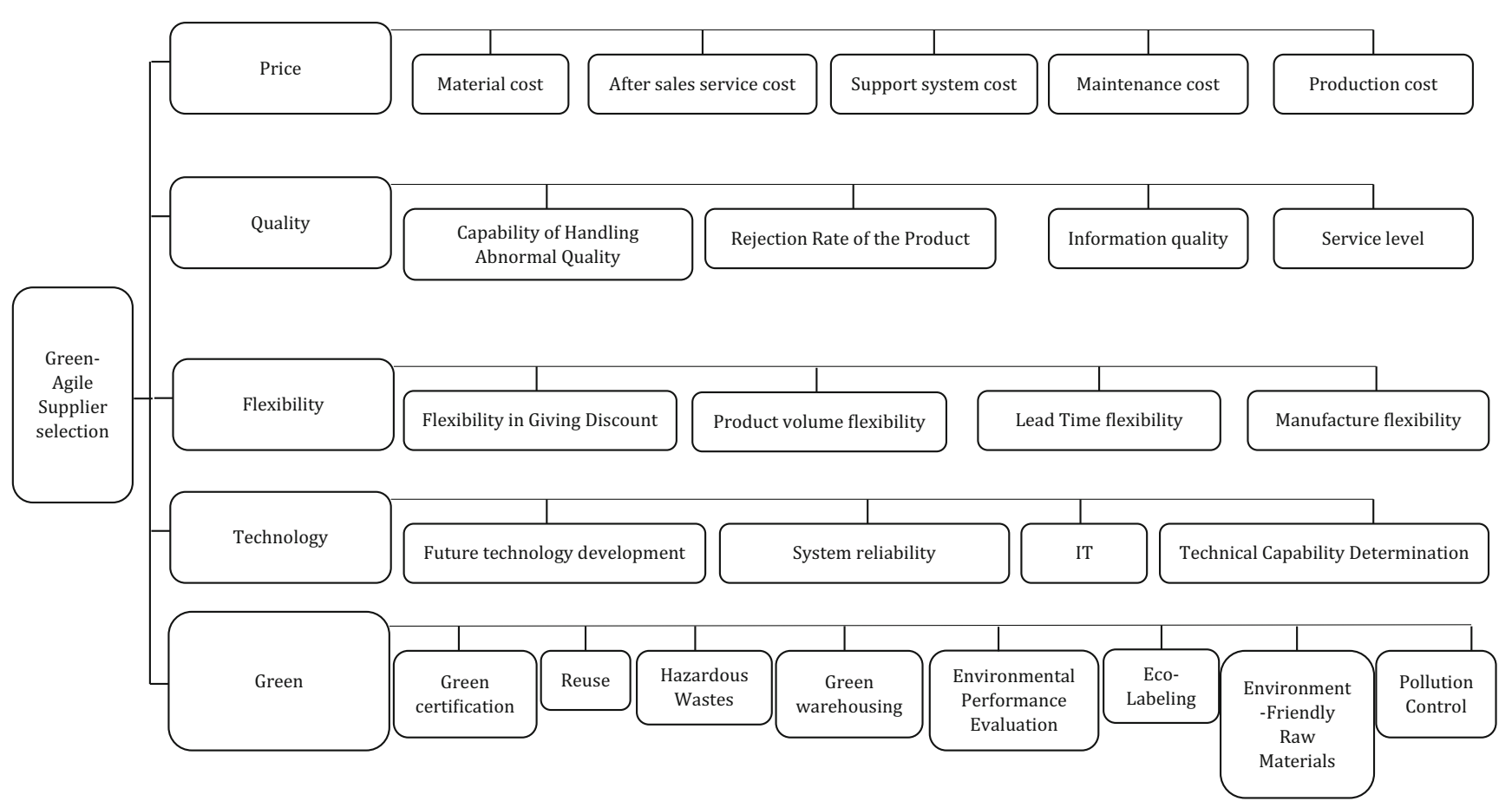

Fig. 3 The aspects and criteria of the green-agile SSP

approach benefits from the advantages of the mentioned methods, concurrently. In this regard, the proposed hybrid fuzzy method has the following advantages: (i) considering interrelationships among indicators using FDEMATEL, (ii) decreasing the number of pair-wise comparisons and also increasing the reliability of the results by applying FBWM within FANP, and (iii) maximizing the group utility and minimizing individual effects applying FVIKOR. Figure 1 shows the stages of the developed method.

\section{Computational results}

\section{Case study}

As aforementioned, due to the importance of medical devices, especially during these days (the pandemic period), this research selects the medical devices industry as a case study. In this regard, a medical devices manufacturing company named Ebtekar Tajhiz Teb, which is located in the Mazandaran Province of Iran, is selected as a case study. The organizations related to the Ministry of Health and Medical Education are the company's customers. This company manufactures several products. The potential suppliers that this firm wants to evaluate their performances between green and agile indicators are located in Tehran (A1), Tabriz (A2), Juybar (A3), Mashhad (A4), and Esfehan (A5). Due to increasing concerns about environmental issues and also according to some government regulations, the firm has to consider environmental indicators in its activities. In this regard, the concept of green supplier selection is meaningful for this company. On the other hand, the fluctuations of the medical devices industry, especially during the recent pandemic (COVID-19), have

Table 5 The average of opinions of experts for identifying interrelationships among aspects

\begin{tabular}{|c|c|c|c|c|c|c|c|c|c|c|c|c|c|c|c|}
\hline \multirow[t]{2}{*}{ Aspect } & \multicolumn{3}{|l|}{ Price } & \multicolumn{3}{|c|}{ Quality } & \multicolumn{3}{|c|}{ Flexibility } & \multicolumn{3}{|c|}{ Technology } & \multicolumn{3}{|c|}{ Green } \\
\hline & $a_{1}$ & $a_{2}$ & $a_{3}$ & $a_{1}$ & $a_{2}$ & $a_{3}$ & $a_{1}$ & $a_{2}$ & $a_{3}$ & $a_{1}$ & $a_{2}$ & $a_{3}$ & $a_{1}$ & $a_{2}$ & $a_{3}$ \\
\hline Price & 0 & 0 & 0 & 1 & 1 & 1 & 1 & 1 & 1 & 1 & 1 & 1 & 1 & 1 & 1 \\
\hline Quality & 8.00 & 9.00 & 9.00 & 0 & 0 & 0 & 1 & 1 & 1 & 1 & 1 & 1 & 1 & 1 & 1 \\
\hline Flexibility & 4.67 & 5.67 & 6.67 & 1 & 1 & 1 & 0 & 0 & 0 & 1 & 1 & 1 & 1 & 1 & 1 \\
\hline Technology & 6.00 & 7.00 & 8.00 & 5.33 & 6.33 & 7.33 & 6.00 & 7.00 & 8.00 & 0 & 0 & 0 & 6.00 & 7.00 & 8.00 \\
\hline Green & 4.00 & 5.00 & 6.00 & 2.67 & 3.67 & 4.67 & 2.00 & 3.00 & 4.00 & 1 & 1 & 1 & 0 & 0 & 0 \\
\hline
\end{tabular}




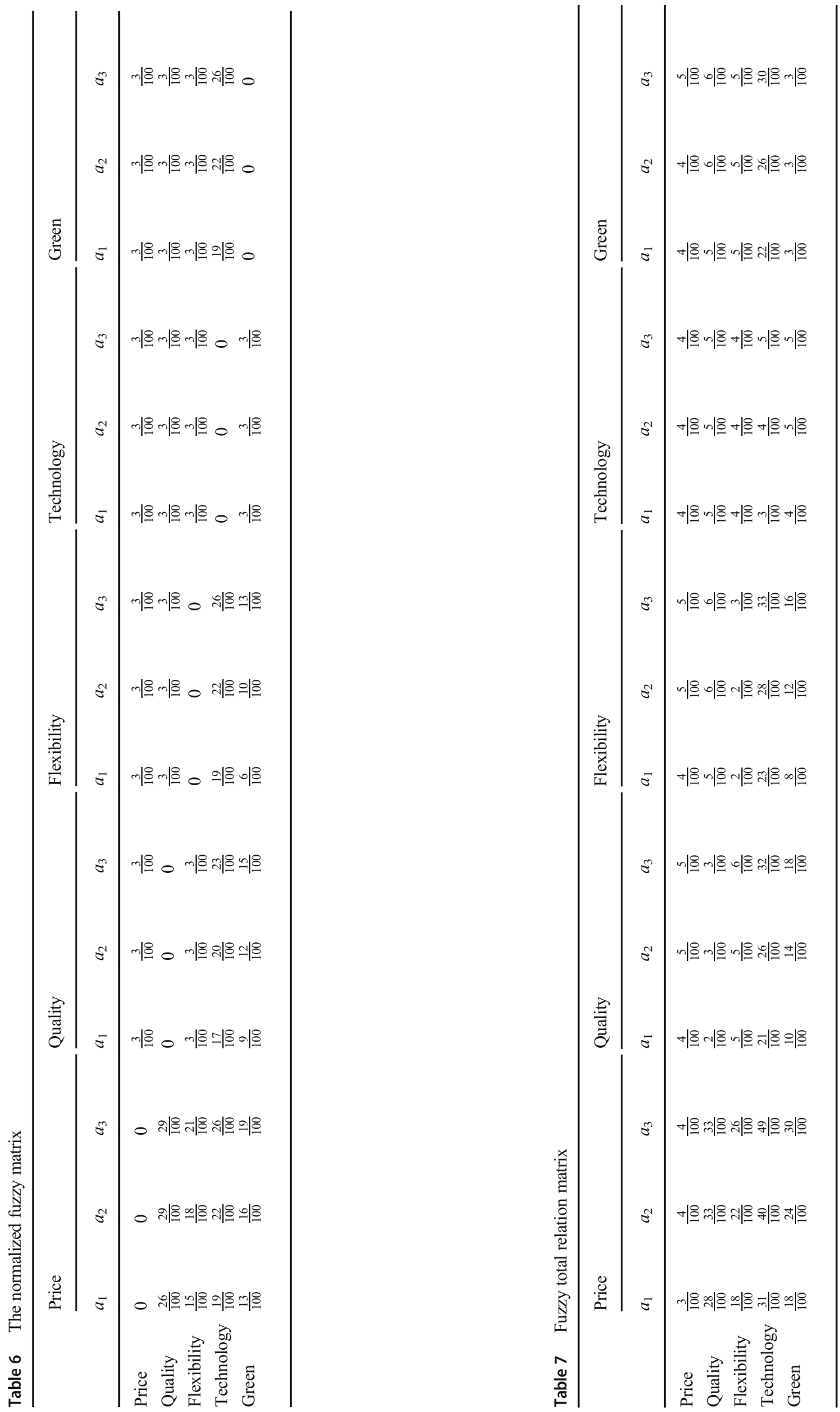


Table 8 The crisp total relation matrix

\begin{tabular}{lllllrl}
\hline & Price & Quality & Flexibility & Technology & Green & D \\
\hline Price & 0.0375 & 0.047 & 0.047 & 0.037557 & 0.045 & 0.214340711 \\
Quality & 0.3198 & 0.028 & 0.059 & 0.046658 & 0.055 & 0.508617332 \\
Flexibility & 0.2182 & 0.054 & 0.023 & 0.042982 & 0.051 & 0.389764845 \\
Technology & 0.3996 & 0.263 & 0.279 & 0.038399 & 0.262 & 0.027 \\
Green & 0.2374 & 0.142 & 0.121 & 0.214341 & 0.44 & 0.576070975 \\
R & 1.2126 & 0.534 & 0.529 & & 0.214340711 \\
\hline
\end{tabular}

caused the mentioned firm interested in implementing the agile feature in their supply chain process. In this regard, considering the agile supplier selection indicators can be helpful for them. Motivated by the mentioned points, we attempt to implement the green-agile supplier selection framework for this firm. Figure 2 shows the main regions of the company and its potential suppliers. It should be noted that the main aspects and criteria of the GASSP are extracted by the combined assistance of existing literature and advice from field experts. The main aspects and criteria for the GASSP are illustrated in Fig. 3. The definitions of the criteria are given in the Supplementary Materials.

\section{Report of the results}

The results of implementing the developed decisionmaking model are presented in this section. At first, we report the steps of calculating weights of the aspects/ criteria, and then we provide the results of ranking suppliers. It should be noted that to obtain comparisons between the aspects and criteria (for FDEMATEL and FBWM), the questionnaires are dispatched among groups of experts. Then, the average of achieved opinions has been applied for calculations.

\section{Calculating weights of the aspects/criteria}

This section is involved four parts: (i) finding interrelationships between the aspects and criteria applying FDEMATEL, (ii) calculating initial weights of the aspects and criteria employing

Table 9 Interrelationships between aspects

\begin{tabular}{llllll}
\hline & Price & Quality & Flexibility & Technology & Green \\
\hline Price & 0 & 0 & 0 & 0 & 0 \\
Quality & 1 & 0 & 0 & 0 & 0 \\
Flexibility & 1 & 0 & 0 & 0 & 0 \\
Technology & 1 & 1 & 1 & 0 & 1 \\
Green & 1 & 1 & 1 & 0 & 0 \\
\hline
\end{tabular}

FBWM, (iii) measuring final weights of the indicators applying FANP, and (iv) ranking the potential suppliers using FVIKOR.

\section{Results of FDEMATEL}

The results of implementing FDEMATEL for aspects are as follows. The average of comparisons between the aspects is given in Table 5. Also, the normalized fuzzy matrix and the total relation fuzzy matrix are given in Tables 6 and 7. In the next step, the crisp total relation matrix is calculated based on the relation (7) and the result are reported in Table 8.

Here, based on the above calculations, the interrelationship between aspects is given in Table 9. In this table, $a_{i j}=$ 1 indicates that the aspect $i$ has effect on aspect $j$. As can be seen in Table 9, quality, flexibility, technology and green aspects affect the price. Technology and green aspects affect the quality and flexibility and also technology affects the green aspect.

Other results of the FDEMATEL method have been provided in Supplementary Materials, in detail.

\section{Results of FBWM}

This section is dedicated to presenting the obtained results by FBWM. Tables 10 and 11 show the average of best-to-other and other-to-worst comparison vectors for the aspects.

Based on the collected data, the results of FBWM are given in Table 12. As can be seen in this table, CR is close to zero that shows the high reliability of the obtained results. Also, the results of the FBWM method for the criteria of each aspect are presented in Tables 13, 14, 15, 16, and 17. It should be noted that the collected data have been reported in the Supplementary Materials.

\section{Results of FANP}

In this section, based on the obtained results by the FBWM and considering interrelationships among the aspects/criteria, the final weights of indicators are calculated. It should be noted that the SuperDecision software has been employed to implement the FANP method (see the Supplementary Materials to observe the decision tree in SuperDecision). To 
Table 10 Best-to-other comparisons for aspects

\begin{tabular}{|c|c|c|c|c|c|c|c|c|c|c|c|c|c|c|c|c|}
\hline \multirow{2}{*}{$\frac{\text { Expert }}{1}$} & \multirow[b]{2}{*}{ Price (best criterion) } & \multicolumn{3}{|l|}{ Price } & \multicolumn{3}{|c|}{ Quality } & \multicolumn{3}{|c|}{ Flexibility } & \multicolumn{3}{|c|}{ Technology } & \multicolumn{3}{|c|}{ Green } \\
\hline & & 1 & 1 & 1 & 1.5 & 2 & 2.5 & 2.5 & 3 & 2.5 & 2.5 & 3 & 3.5 & 1.5 & 2 & 2.5 \\
\hline 2 & & 1 & 1 & 1 & 0.667 & 1 & 1.5 & 1.5 & 2 & 2.5 & 2.5 & 3 & 3.5 & 0.67 & 1 & 1.5 \\
\hline 3 & & 1 & 1 & 1 & 1.5 & 2 & 2.5 & 1.5 & 2 & 2.5 & 2.5 & 3 & 3.5 & 0.67 & 1 & 1.5 \\
\hline Average & & 1.00 & 1.00 & 1.00 & 1.22 & 1.67 & 2.17 & 1.83 & 2.33 & 2.50 & 2.50 & 3.00 & 3.50 & 0.94 & 1.33 & 1.83 \\
\hline
\end{tabular}

directly enter the obtained results of the FBWM in the SuperDecision software, we use the "Misc $\rightarrow$ Direct data entry" toolbar in the pair-wise comparison section. Table 18 shows the final weights of the criteria. As can be seen in this table, material costs, environmental performance evaluation, manufacture flexibility, service level, and system reliability are the most important criteria. To better understand, Fig. 4 depicts the obtained results. On the other side, future technology development and information quality are considered as the least important criteria for the research problem. Now, we discuss about the criteria weights in order to show the impact of considering interrelationships among them. In this regard, we calculate the weight of the material cost criteria without considering interrelationships (only using the FBWM), which is equal to $0.3301739 \times 0.2986822=0.072910$. However, by considering the interrelationships, the final weight for the service level is equal to 0.079451 . This point shows that the weight of this criteria is increased when the interrelationships among the criteria are considered. Therefore, considering the interrelationships among the criteria seems to be important in

Table 11 Other-to-Worst comparisons for aspects

\begin{tabular}{|c|c|c|c|c|}
\hline \multirow[b]{2}{*}{$\begin{array}{l}\text { Expert } \\
\text { Aspect }\end{array}$} & \multicolumn{3}{|c|}{ Technology (Worst criterion) } & \multirow[b]{2}{*}{ Average } \\
\hline & 1 & 2 & 3 & \\
\hline \multirow[t]{3}{*}{ Price } & 2.5 & 2.5 & 2.5 & 2.50 \\
\hline & 3 & 3 & 3 & 3.00 \\
\hline & 3.5 & 3.5 & 3.5 & 3.50 \\
\hline \multirow[t]{3}{*}{ Quality } & 1.5 & 2.5 & 1.5 & 1.83 \\
\hline & 2 & 3 & 2 & 2.33 \\
\hline & 2.5 & 3.5 & 2.5 & 2.83 \\
\hline \multirow[t]{3}{*}{ Flexibility } & 1.5 & 1.5 & 1.5 & 1.50 \\
\hline & 2 & 2 & 2 & 2.00 \\
\hline & 2.5 & 2.5 & 2.5 & 2.50 \\
\hline \multirow[t]{3}{*}{ Technology } & 1 & 1 & 1 & 1.00 \\
\hline & 1 & 1 & 1 & 1.00 \\
\hline & 1 & 1 & 1 & 1.00 \\
\hline \multirow[t]{3}{*}{ Green } & 1.5 & 2.5 & 2.5 & 2.17 \\
\hline & 2 & 3 & 3 & 2.67 \\
\hline & 2.5 & 3.5 & 3.5 & 3.17 \\
\hline
\end{tabular}

the research problem. To better understand, we have illustrated the final weights of criteria in the two different modes (with the interrelationships and without the interrelationships) in Fig. 5.

\section{Ranking the suppliers using FVIKOR}

In this section, the potential alternatives are ranked by applying the FVIKOR method. The calculations of this method (forming decision matrix, calculating normalized decision matrix, measuring $S j$ and $R j$ ) are given in the Supplementary Materials. It should be noted that $S_{j}, R_{j}$ , and $Q_{j}$ are calculated for each alternative considering $v$ $=0.5$ for the weights of individual utility and regret. Figure 6 shows the values of $Q j$ and also the ranking of the suppliers. According to this figure, the ranking of the suppliers is as follows: (1) A1, (2) A5, (3) A2, (4) A4, (5) A3.

\section{Discussions}

This section is dedicated to comparing the proposed method with the common methods presenting sensitivity analysis and some theoretical and managerial implications.

\section{Comparing with the other common methods}

To show the performance and validity of the proposed decision-making framework, this section is devoted to comparing the obtained results by the proposed approach with FAHP as one of the widely used decision-making methods. Table 19 compares the results of the proposed approach with the FAHP method. As can be seen in this table, although there are some minor differences between the weights obtained, which has been occurred due to considering the interrelationships in the proposed approach, the results of both methods are close to each other. In both methods, the top five indicators are the same (material costs, environmental performance evaluation, manufacture flexibility, service level, and system reliability), but there are some differences in the rank of the other indicators that show the effect of considering 
Table 12 Initial weights of the aspects obtained by FBWM

\begin{tabular}{lcccc}
\hline Aspect & Price & Quality & Flexibility & Technology \\
\hline Optimal weights (OWs) & 0.2986822 & 0.2032051 & 0.1585216 & 0.1076069 \\
$\xi^{*}=0.50000 \mathrm{CI}=6.69 \rightarrow \mathrm{CR}=\frac{0.50000}{6.69}=0.0747$ & & & 0.2319842 \\
\hline
\end{tabular}

Table 13 Initial weights of the criteria of price aspect obtained by FBWM

\begin{tabular}{|c|c|c|c|c|c|}
\hline Criteria & Material cost & After sales service cost & Support system cost & Maintenance cost & Production cost \\
\hline OWs & 0.3301739 & 0.2031960 & 0.09567348 & 0.1374492 & 0.2335074 \\
\hline \multicolumn{6}{|c|}{$\xi^{*}=0.6715729 \mathrm{CI}=8.04 \rightarrow \mathrm{CR}=\frac{0.6715729}{8.04}=0.0835$} \\
\hline
\end{tabular}

interrelationships. On the other side, it should be noted that the computing burden in the proposed method is reduced, drastically. In this regard, in the FAHP method for the $k$ decision-makers and $n=25$ criteria, there are $\frac{k \times 25 \times 24}{2}=300 k$. However, for the proposed method, there are $k \times 2 \times 25=50 k$. This point shows the significant advantage of the proposed method over the traditional methods in terms of the computing burden.

\section{Sensitivity analysis}

In this section, to evaluate the robustness of the proposed model, sensitivity analysis via changing the defuzzification method is conducted. To do this, we implement the proposed framework using different defuzzification methods such as bisector of area (BOA), center of area (COA), smallest of maximum (SOM), mean of maximum (MOM), and largest of maximum (LOM) (see Amindoust et al. 2012; Amindoust and Saghafinia 2017 for more study). The results of conducting sensitivity analysis are given in Table 20. Based on the obtained results, changing the defuzzification method has no significant effect on the results, and the rankings of the suppliers are relatively similar. In this regard, supplier A1 is the best in all of the defuzzification methods, which indicates that the model is robust and valid.

\section{Theoretical implications}

Nowadays, owing to the drastic increase in the competition in the market, the importance of the supply chain management (SCM) problem has increased more than in previous years. In this regard, one of the most important fields of SCM is the supplier selection problem that aims at selecting the best suppliers between the potential ones. Due to the complexity of the SSP especially when gathering the precise data is difficult, developing an efficient fuzzy decision-making method can help the managers and decision-makers to make the best decision about the SSP problem. Hence, in this study, we have attempted to develop a hybrid fuzzy decision-making approach to the supplier selection problem in which green and agile indicators have been considered. The main theoretical contributions of this research are as follows:

Table 14 Initial weights of the criteria of quality aspect obtained by FBWM

\begin{tabular}{|c|c|c|c|c|}
\hline Criteria & Capability of Handling abnormal quality & Rejection rate of the product & Information quality & Service level \\
\hline OWs & 0.2856111 & 0.2416994 & 0.1138889 & 0.3588005 \\
\hline \multicolumn{5}{|c|}{$\xi^{*}=0.5173657 \mathrm{CI}=6.69 \rightarrow \mathrm{CR}=\frac{0.5173657}{6.69}=0.07733$} \\
\hline
\end{tabular}

Table 15 Initial weights of the criteria of flexibility aspect obtained by FBWM

\begin{tabular}{lllll}
\hline Criteria & Flexibility in giving discount & Product volume flexibility & Lead time flexibility & Manufacture flexibility \\
\hline OWs & 0.1338317 & 0.2408513 & 0.2408513 & 0.3844656 \\
$\xi^{*}=0.4783141 \mathrm{CI}=6.69 \rightarrow \mathrm{CR}=\frac{0.4783141}{6.69}=0.0715$ & & & \\
\hline
\end{tabular}


Table 16 Initial weights of the criteria of technology aspect obtained by FBWM

\begin{tabular}{|c|c|c|c|c|}
\hline Criteria & Future technology development & System reliability & IT & Technical capability determination \\
\hline OWs & 0.1646762 & 0.3077986 & 0.3015506 & 0.2259746 \\
\hline \multicolumn{5}{|c|}{$\xi^{*}=0.2639320 \mathrm{CI}=3.8 \rightarrow \mathrm{CR}=\frac{0.2639320}{3.8}=0.0694$} \\
\hline
\end{tabular}

Table 17 Initial weights of the criteria of green aspect obtained by FBWM

\begin{tabular}{|c|c|c|c|c|c|c|c|c|}
\hline Criteria & $\begin{array}{l}\text { Green } \\
\text { certification }\end{array}$ & Reuse & $\begin{array}{l}\text { Hazardous } \\
\text { Wastes }\end{array}$ & $\begin{array}{l}\text { Green } \\
\text { warehousing }\end{array}$ & $\begin{array}{l}\text { Environmental } \\
\text { Performance Evaluation }\end{array}$ & $\begin{array}{l}\text { Eco- } \\
\text { Labeling }\end{array}$ & $\begin{array}{l}\text { Environment-Friendly } \\
\text { Raw Materials }\end{array}$ & $\begin{array}{l}\text { Pollution } \\
\text { Control }\end{array}$ \\
\hline OWs & 0.1160265 & 0.1138273 & 0.1384807 & 0.06421330 & 0.2187943 & 0.08991425 & 0.1483314 & 0.1104122 \\
\hline \multicolumn{9}{|c|}{$\xi^{*}=0.6163679 \mathrm{CI}=6.69 \rightarrow \mathrm{CR}=\frac{0.6163679}{6.69}=0.09213$} \\
\hline
\end{tabular}

i. This study is the first research that has investigated the SSP problem with simultaneous consideration of the green-agile indicators under the fuzzy environment. In this regard, we defined five aspects that included 25 criteria for the green-agile supplier selection in the medical devices industry according to the experts' opinions and the literature.

Table 18 Final weights of criteria

\begin{tabular}{ll}
\hline Criteria & Final weight \\
\hline Material cost (C1) & 0.105192 \\
After sales service cost (C2) & 0.024379 \\
Support system cost (C3) & 0.042479 \\
Maintenance cost (C4) & 0.035722 \\
Production cost (C5) & 0.047784 \\
Capability of handling abnormal quality (C6) & 0.025369 \\
Rejection rate of the product (C7) & 0.022616 \\
Information quality (C8) & 0.011138 \\
Service level (C9) & 0.079451 \\
Flexibility in giving discount (C10) & 0.021215 \\
Product volume flexibility (C11) & 0.03818 \\
Lead time flexibility (C12) & 0.038179 \\
Manufacture flexibility (C13) & 0.081946 \\
Future technology development (C14) & 0.010451 \\
System reliability (C15) & 0.072479 \\
IT (C16) & 0.041451 \\
Technical capability determination (17) & 0.013451 \\
Green certification (C18) & 0.049913 \\
Reuse (C19) & 0.01298 \\
Hazardous wastes (C20) & 0.025867 \\
Green warehousing (C21) & 0.027836 \\
Environmental performance evaluation (C22) & 0.092013 \\
Eco-Labeling (C23) & 0.030659 \\
Environment-friendly raw materials (C24) & 0.032342 \\
Pollution Control (C25) & 0.02598 \\
\hline &
\end{tabular}

ii. This research has developed a hybrid fuzzy decisionmaking approach (integrated FDEMATEL-FBWMFANP-FVIKOR), which has benefited from the advantage of the mentioned methods simultaneously. This method has the following advantages: (a) considering the interrelationships between aspects and criteria, (b) decreasing cognitive burden, (c) increasing the reliability of the results, and (d) minimizing individual effects and maximizing the group utility.

iii. Based on the obtained results, "quality," "flexibility," "technology," and "green' aspects influence the "price" aspect. On the other side, "technology" and "green" aspects influence both "quality" and "flexibility" aspects. Finally, the "technology" aspect affects the "green" aspect. Also, the results showed that material costs, environmental performance evaluation, manufacture flexibility, service level, and system reliability are the most important criteria. The main reasons for achieving these results are as follows:

a. As mentioned, the price aspect is influenced by the "quality," "flexibility," "technology," and "green" aspects. In this regard, undoubtedly, when the quality of a product is at a higher level, the price of it is increased, too. On the other side, usually, suppliers with higher flexibility have a higher price for contracting. Also, usually, the price of working with a supplier is affected by the technology used by this supplier. Eventually, the level of the greenness of a supplier affects the price due to its impact on the activities of the supplier.

b. The main reason for the interrelationship among the technology and green aspects is that there are different types of technologies with different prices and pollution. Usually, the technology with a higher price has lower pollution. Hence, using technologies with lower pollution can increase the level of greenness. 
Fig. 4 The final weights of greenagile criteria

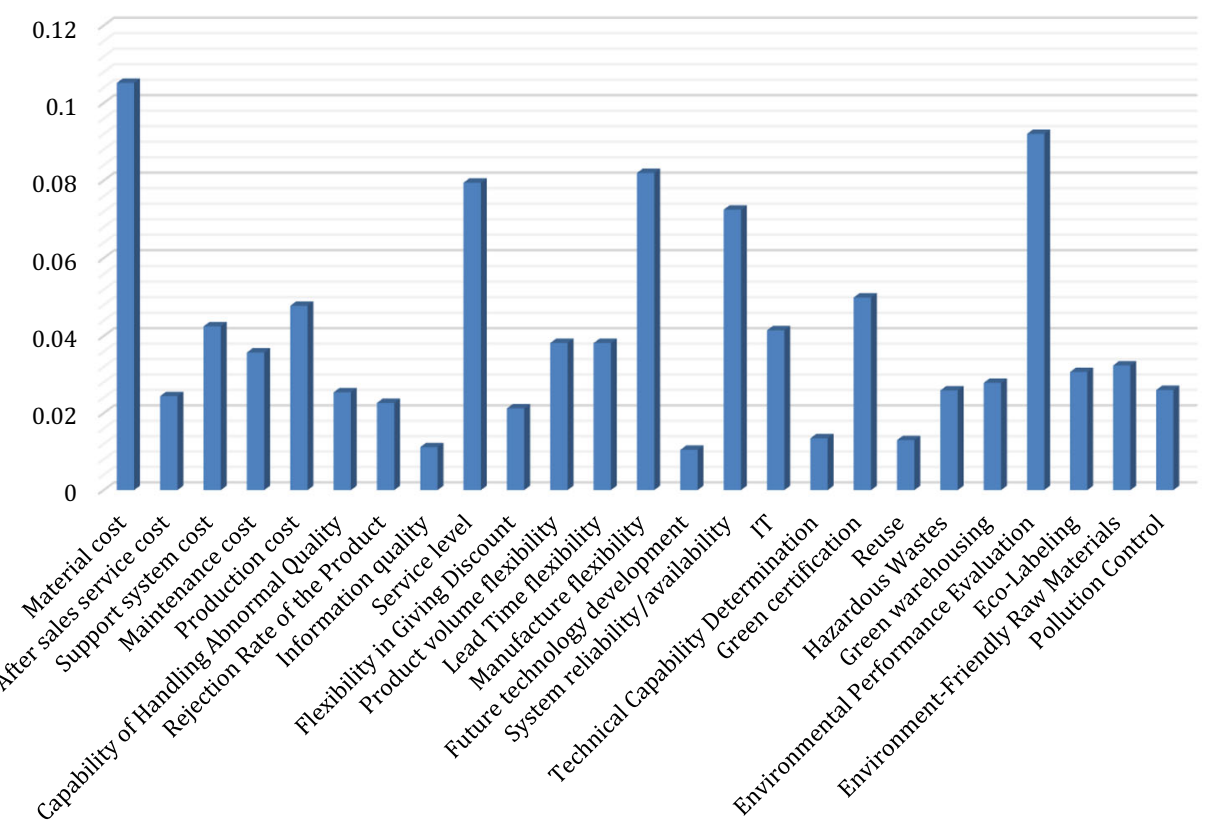

c. The material costs are considered as the most important criteria for the research problem. Due to the importance of the economic aspects in the business environment, it is rational that costs are considered as the most important criteria for selecting the suppliers. On the other side, environmental performance evaluation has become the second most important criterion that shows the importance of the green aspect in the view of decision-makers. Albeit, the existence of some governmental and international regulations has forced the firms to consider the green aspect as an important indicator. Finally, the agility footprint in the research problem has been seen by devoting manufacture flexibility, service level, and system reliability as the third, fourth, and fifth important criteria.

iv. Based on the obtained results, the consistency ratios of all outputs are less than 0.1 , which shows that the consistency of the computations is good and the reliability of the results is high.
Fig. 5 Comparing the final weights of criteria in the two different modes

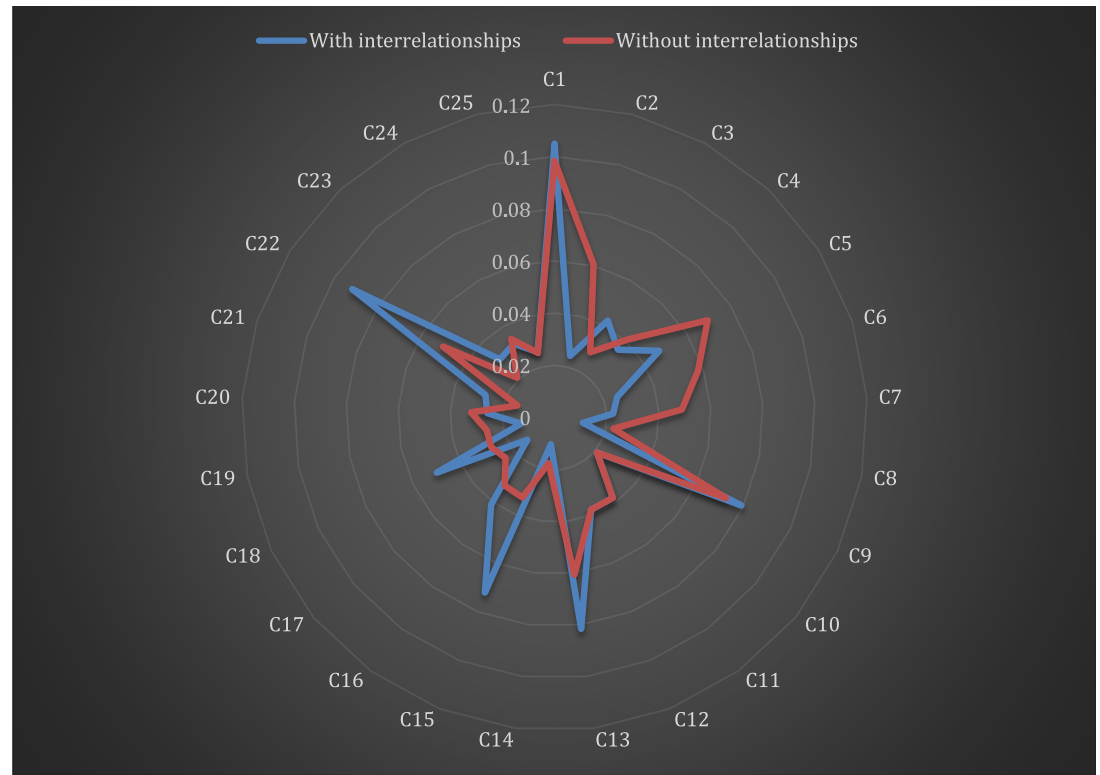


Fig. 6 The results of FVIKOR

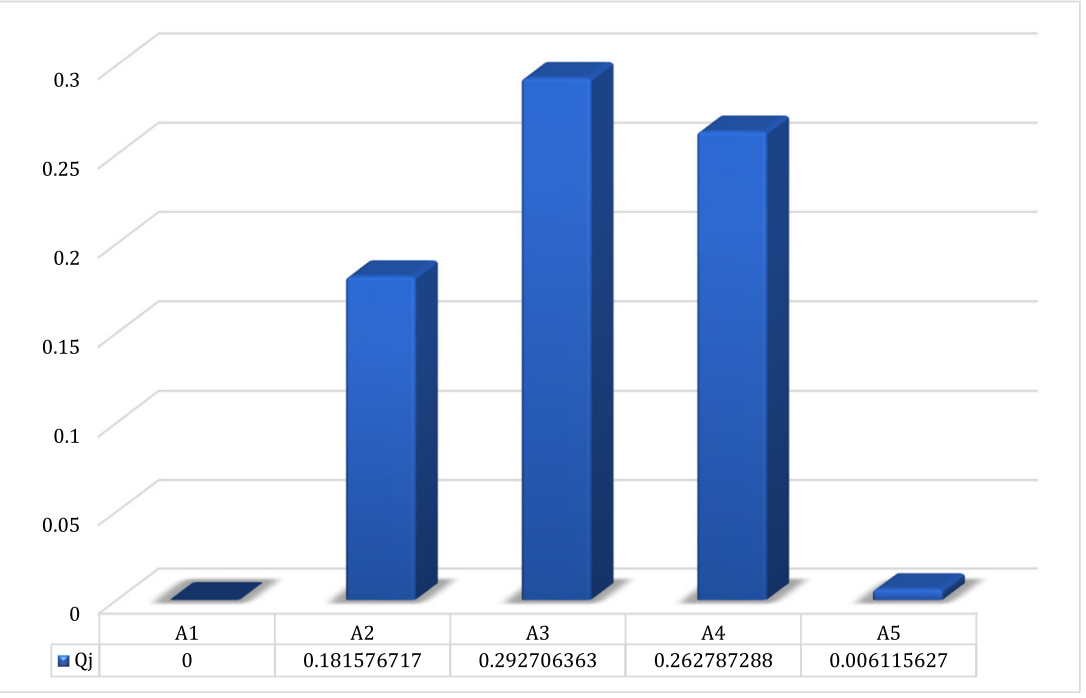

\section{Managerial implications}

This research investigated the green-agile supplier selection problem and can give a nice perspective to the SC managers

Table 19 comparing the proposed method with FAHP

\begin{tabular}{|c|c|c|}
\hline Criteria & Weight (the proposed method) & Weight (FAHP) \\
\hline $\mathrm{C} 1$ & 0.105192 & 0.109975 \\
\hline $\mathrm{C} 2$ & 0.024379 & 0.021405 \\
\hline $\mathrm{C} 3$ & 0.042479 & 0.042162 \\
\hline $\mathrm{C} 4$ & 0.035722 & 0.036028 \\
\hline $\mathrm{C} 5$ & 0.047784 & 0.048104 \\
\hline C6 & 0.025369 & 0.021245 \\
\hline C7 & 0.022616 & 0.021307 \\
\hline $\mathrm{C} 8$ & 0.011138 & 0.010982 \\
\hline C9 & 0.079451 & 0.080075 \\
\hline $\mathrm{C} 10$ & 0.021215 & 0.021083 \\
\hline C11 & 0.03818 & 0.03951 \\
\hline $\mathrm{C} 12$ & 0.038179 & 0.039084 \\
\hline $\mathrm{C} 13$ & 0.081946 & 0.082385 \\
\hline $\mathrm{C} 14$ & 0.010451 & 0.010876 \\
\hline $\mathrm{C} 15$ & 0.072479 & 0.072853 \\
\hline C16 & 0.041451 & 0.041926 \\
\hline $\mathrm{C} 17$ & 0.013451 & 0.013108 \\
\hline $\mathrm{C} 18$ & 0.049913 & 0.049728 \\
\hline C19 & 0.01298 & 0.01301 \\
\hline $\mathrm{C} 20$ & 0.025867 & 0.025715 \\
\hline $\mathrm{C} 21$ & 0.027836 & 0.026021 \\
\hline $\mathrm{C} 22$ & 0.092013 & 0.095307 \\
\hline $\mathrm{C} 23$ & 0.030659 & 0.030137 \\
\hline $\mathrm{C} 24$ & 0.032342 & 0.032526 \\
\hline $\mathrm{C} 25$ & 0.02598 & 0.02414 \\
\hline
\end{tabular}

for selecting the best suppliers for their company based on green and agile indicators. At first, this paper formed a list of indicators including five aspects and 25 criteria for combining green indicators with agile indicators. Then, a hybrid fuzzy decision-making method is developed to calculate the weights of the indicators and rank the potential suppliers. By employing the proposed model, leaders of the supply chain can determine the most important green-agile indicators and also select the suppliers that have good performance in terms of greenness and agility. Besides, the formed list of indicators can be very useful and applicable for the managers of the medical devices companies that want to understand the concepts of greenness and agility in supplier selection problem.

\section{Remarks}

In this section, some discussions about the insight of the main results of this study are provided. In general, this study has developed a comprehensive decision-making framework to investigate the green-agile supplier selection for the medical devices industry. To do this, a hybrid fuzzy method based on the FDEMATEL, FBWM, FANP, and FVIKOR is proposed.

Table 20 Results of the sensitivity analysis

\begin{tabular}{llllll}
\hline & BOA & COA & SOM & MOM & LOM \\
\hline A1 & 0 & 0 & 0 & 0 & 0 \\
A2 & 0.19246 & 0.17987 & 0.18504 & 0.19047 & 0.18304 \\
A3 & 0.28475 & 0.27193 & 0.28106 & 0.29019 & 0.28362 \\
A4 & 0.27613 & 0.26984 & 0.27052 & 0.26805 & 0.27140 \\
A5 & 0.00865 & 0.00740 & 0.00741 & 0.00678 & 0.00804 \\
\hline
\end{tabular}


The results illustrated the interrelationships among the aspects and criteria, the importance of indicators, and the rank of the potential suppliers. The following remarks can be obtained from the results of this study:

- Base on the results, the "quality," "flexibility," "technology," and "green" aspects affect the price criteria. In this regard, managers should be aware that paying pure attention to the financial aspect (price) is not enough, and they should also consider the aspects that affect it.

- Interrelationship among the technology, flexibility, and green aspects show the relationship between agile and green concepts. This point shows that indicators related to the green and agile features have interrelationships to each other and demonstrate the importance of simultaneous consideration of both features.

- Results showed that the material cost, environmental performance evaluation, manufacture flexibility, service level, and system reliability are the more important criteria. The existence of the different types of criteria in the above list shows the importance of all considered aspects. In this regard, material cost belongs to the price aspect, environmental performance evaluation belongs to the green aspect, manufacture flexibility belongs to the flexibility aspect, service level belongs to the quality aspect, and system reliability belongs to the technology aspect. As a result, all the considered aspects are important. Hence, this study can give a good perspective to the managers for selecting their suppliers according to green and agile features.

\section{Conclusions and future suggestions}

This research addressed the supplier selection problem with simultaneous consideration of the green and agile indicators for the medical devices industry. To do this, at first, the main aspects and criteria of the research problem were identified based on the literature and experts. Then, a hybrid fuzzy decision-making approach was developed based on the FDEMATEL, FBWM, FANP, and FVIKOR methods to calculate the importance of the indicators and rank the potential suppliers. In this method, firstly, the interrelationships between indicators were determined applying FDEMATEL. Afterward, the weights of the indicators were calculated by integrated FBWM-FANP. Eventually, the supplies were ranked employing FVIKOR. The proposed approach simultaneously has some advantages such as (a) identifying interrelationships among indicators, (b) measuring weights of the indicators, (c) reducing the computing burden, (d) increasing the reliability of results, and (e) ranking the suppliers considering the group utility. Then, due to the importance of the medical devices industry, especially during the recent pandemic (COVID-19), a real-world case study in the medical devices industry in Iran is considered as a case study in this research. Afterward, the proposed hybrid method was implemented, and the obtained results showed the efficiency and performance of the proposed approach. The findings showed that material costs, environmental performance evaluation, manufacture flexibility, service level, and system reliability are the most important criteria. Based on the obtained results, all the consistency rates are less than 0.1 , which demonstrates the reliability of the results. The results of conducting sensitivity analysis showed that by changing the defuzzification methods, there is no significant change in the obtained results that demonstrates the validity of the proposed approach. On the other hand, results of comparing the proposed framework with the FAHP method confirmed the validity of the developed approach.

Future research can study the customer-based green-agile supplier selection by combining the QFD, Markov chain, and the proposed hybrid methods. Also, researchers can use the artificial intelligence approach to investigate the green-agile supplier selection problem and compare the results with the current study. Considering sustainable indicators and investigating the sustainable-agile supplier selection problem is another direction for future studies.

Supplementary Information The online version contains supplementary material available at https://doi.org/10.1007/s11356-021-14690-z.

Author contribution Fatemeh Alamroshan: conceptualization, methodology, writing - original draft preparation, visualization

Mahyar La'li: methodology, software, investigation, validation, writing - reviewing and editing

Mohsen Yahyaei: supervision, investigation, validation, writing reviewing and editing

Data Availability The related data have been presented in supplementary materials.

\section{Declarations}

Ethics approval and consent to participate Not applicable

Consent for publication Not applicable

Conflict of interest The authors declare no competing interests.

\section{References}

Alimardani M, Hashemkhani Zolfani S, Aghdaie MH, Tamošaitienė J (2013) A novel hybrid SWARA and VIKOR methodology for supplier selection in an agile environment. Technol Econ Dev Econ 19: 533-548 
Altan A, Karasu S (2019) The effect of kernel values in support vector machine to forecasting performance of financial time series. J Cogn Syst 4:17-21

Amindoust A, Ahmed S, Saghafinia A, Bahreininejad A (2012) Sustainable supplier selection: a ranking model based on fuzzy inference system. Appl Soft Comput 12:1668-1677

Amindoust A, Saghafinia A (2017) Textile supplier selection in sustainable supply chain using a modular fuzzy inference system model. J Text Inst 108:1250-1258

Aslan O, Altan A, Hacioglu R (2017) The control of blast furnace top gas pressure by using fuzzy PID. In: Proceedings of the Fifth International Conference on Advances in Mechanical and Robotics Engineering-AMRE. pp 22-26

Banaeian N, Mobli H, Fahimnia B, Nielsen IE, Omid M (2018) Green supplier selection using fuzzy group decision making methods: a case study from the agri-food industry. Comput Oper Res 89:337347

BaykasoğLu A, KaplanoğLu V, DurmușOğLu ZDU, ȘAhin C (2013) Integrating fuzzy DEMATEL and fuzzy hierarchical TOPSIS methods for truck selection. Expert Syst Appl 40:899-907

Beikkhakhian Y, Javanmardi M, Karbasian M, Khayambashi B (2015) The application of ISM model in evaluating agile suppliers selection criteria and ranking suppliers using fuzzy TOPSIS-AHP methods. Expert Syst Appl 42:6224-6236

Bera AK, Jana DK, Banerjee D, Nandy T (2021) A decision-making framework for green supplier selection using FAHP and Taguchi quality loss functions. In: Proceedings of the Fifth International Conference on Mathematics and Computing. Springer, pp 137-154

Bhattacharya K, De SK (2021) A robust two layer green supply chain modelling under performance based fuzzy game theoretic approach. Comput Ind Eng 152:107005

Bhattacharya K, De SK, Khan A, Nayak PK (2021) Pollution sensitive global crude steel production-transportation model under the effect of corruption perception index. OPSEARCH:1-25

Çalık A (2021) A novel Pythagorean fuzzy AHP and fuzzy TOPSIS methodology for green supplier selection in the Industry 4.0 era. Soft Comput 25:2253-2265

Chen J, Zeng S, Zhang C (2018) An OWA distance-based, single-valued neutrosophic linguistic topsis approach for green supplier evaluation and selection in low-carbon supply chains. Int J Environ Res Public Health 15:1439

Ciccullo F, Pero M, Caridi M, Gosling J, Purvis L (2018) Integrating the environmental and social sustainability pillars into the lean and agile supply chain management paradigms: a literature review and future research directions. J Clean Prod 172:2336-2350

De SK (2018) Triangular dense fuzzy lock sets. Soft Comput 22:72437254

De SK (2020) On degree of fuzziness and fuzzy decision making. Cybern Syst 51:600-614

De SK (2021) Solving an EOQ model under fuzzy reasoning. Appl Soft Comput 99:106892

De SK, Mahata GC (2019) An EPQ model for three-layer supply chain with partial backordering and disruption: triangular dense fuzzy lock set approach. Sādhanā 44:1-15

De SK, Mahata GC (2020) A production inventory supply chain model with partial backordering and disruption under triangular linguistic dense fuzzy lock set approach. Soft Comput 24:5053-5069

De SK, Mahata GC (2021) Solution of an imperfect-quality EOQ model with backorder under fuzzy lock leadership game approach. Int J Intell Syst 36:421-446

De SK, Sana SS (2018) Two-layer supply chain model for Cauchy-type stochastic demand under fuzzy environment. Int J Intell Comput Cybern

Ecer F (2021) Sustainability assessment of existing onshore wind plants in the context of triple bottom line: a best-worst method (BWM) based MCDM framework. Environ Sci Pollut Res 1-17
Fallahpour A, Kazemi N, Molani M et al (2018) An intelligence-based model for supplier selection integrating data envelopment analysis and support vector machine. Iran J Manag Stud 11:209-241

Fallahpour A, Nayeri S, Sheikhalishahi M et al (2021) A hyper-hybrid fuzzy decision-making framework for the sustainable-resilient supplier selection problem: a case study of Malaysian Palm oil industry. Environ Sci Pollut Res:1-21

Fallahpour A, Wong KY, Rajoo S, Mardani A (2019) An integrated fuzzy carbon management-based model for suppliers' performance evaluation and selection in green supply chain management. Int J Fuzzy Syst $1-12$

Foroozesh N, Jolai F, Mousavi SM, Karimi B (2021) A new fuzzystochastic compromise ratio approach for green supplier selection problem with interval-valued possibilistic statistical information. Neural Comput Appl 1-19

Galankashi MR, Helmi SA (2016) Assessment of hybrid lean-agile (Leagile) supply chain strategies. J Manuf Technol Manag

Gao H, Ju Y, Gonzalez EDRS, Zhang W (2020) Green supplier selection in electronics manufacturing: an approach based on consensus decision making. J Clean Prod 245:118781

Goker N, Dursun M, Cedolin M (2020) A novel IFCM integrated distance based hierarchical intuitionistic decision making procedure for agile supplier selection. J Intell Fuzzy Syst 38:653-662

Graham G, Freeman J, Chen T (2015) Green supplier selection using an AHP-Entropy-TOPSIS framework. Supply Chain Manag An Int J

Guo S, Zhao H (2017) Fuzzy best-worst multi-criteria decision-making method and its applications. Knowledge-Based Syst 121:23-31

Haeri SAS, Rezaei J (2019) A grey-based green supplier selection model for uncertain environments. J Clean Prod 221:768-784

Hasan MA, Shankar R, Sarkis J (2008) Supplier selection in an agile manufacturing environment using data envelopment analysis and analytical network process. Int J Logist Syst Manag 4:523-550

Hocine A, Guellil MS, Dogan E, Ghouali S, Kouaissah N (2020) A fuzzy goal programming with interval target model and its application to the decision problem of renewable energy planning. Environ Ecol Stat 27:527-547

Javad MOM, Darvishi M, Javad AOM (2020) Green supplier selection for the steel industry using BWM and fuzzy TOPSIS: a case study of Khouzestan steel company. Sustain Futur 2:100012

Kilic HS, Yalcin AS (2020) Modified two-phase fuzzy goal programming integrated with IF-TOPSIS for green supplier selection. Appl Soft Comput 93:106371

Li Y, Diabat A, Lu C-C (2020) Leagile supplier selection in Chinese textile industries: a DEMATEL approach. Ann Oper Res 287: 303-322

Luo X, Wu C, Rosenberg D, Barnes D (2009) Supplier selection in agile supply chains: an information-processing model and an illustration. J Purch Supply Manag 15:249-262

Mabrouk N (2021) Green supplier selection using fuzzy Delphi method for developing sustainable supply chain. Decis Sci Lett 10:63-70

Mehrbakhsh S, Ghezavati V (2020) Mathematical modeling for green supply chain considering product recovery capacity and uncertainty for demand. Environ Sci Pollut Res 27:44378-44395

Mohammadzadeh AK, Ghafoori S, Mohammadian A, Mohammadkazemi R, Mahbanooei B, Ghasemi R (2018) A fuzzy analytic network process (FANP) approach for prioritizing internet of things challenges in Iran. Technol Soc 53:124-134

Mousakhani S, Nazari-Shirkouhi S, Bozorgi-Amiri A (2017) A novel interval type-2 fuzzy evaluation model based group decision analysis for green supplier selection problems: a case study of battery industry. J Clean Prod 168:205-218

Musani S, Jemain AA (2015) Ranking schools' academic performance using a fuzzy VIKOR. In: Journal of Physics: Conference Series. pp $1-10$ 
Nayeri S, Paydar MM, Asadi-Gangraj E, Emami S (2020) Multiobjective fuzzy robust optimization approach to sustainable closed-loop supply chain network design. Comput Ind Eng 106716

Nayeri S, Tavakoli M, Tanhaeean M, Jolai F (2021) A robust fuzzy stochastic model for the responsive-resilient inventory-location problem: comparison of metaheuristic algorithms. Ann Oper Res $1-41$

Opricovic S, Tzeng G-H (2004) Compromise solution by MCDM methods: a comparative analysis of VIKOR and TOPSIS. Eur J Oper Res 156:445-455

Özdemir A, Özkan A, Günkaya Z, Banar M (2020) Decision-making for the selection of different leachate treatment/management methods: the ANP and PROMETHEE approaches. Environ Sci Pollut Res 27: 19798-19809

Pınar A, Babak Daneshvar R, Özdemir YS (2021) q-Rung orthopair fuzzy TOPSIS method for green supplier selection problem. Sustainability 13:985

Rezaei J (2015) Best-worst multi-criteria decision-making method. Omega 53:49-57. https://doi.org/10.1016/j.omega.2014.11.009

Rouyendegh BD, Yildizbasi A, Üstünyer P (2020) Intuitionistic fuzzy TOPSIS method for green supplier selection problem. Soft Comput 24:2215-2228

Sazvar Z, Zokaee M, Tavakkoli-Moghaddam R et al (2021) Designing a sustainable closed-loop pharmaceutical supply chain in a competitive market considering demand uncertainty, manufacturer's brand and waste management. Ann Oper Res:1-32
Simon HA (1977) The new science of management decision. PrenticeHall, Englewood Cliffs

Sunay A, Altan A, Belge E, Hacioğlu R (2020) Investigation of route tracking performance with adaptive PID controller in quadrotor. Eur J Tech 10:160-172

Wei C, Wu J, Guo Y, Wei G (2021) Green supplier selection based on CODAS method in probabilistic uncertain linguistic environment. Technol Econ Dev Econ 1-20

Wu C, Barnes D (2009) A model for continuous improvement in supplier selection in agile supply chains. Knowl Process Manag 16:85-110

Wu C, Barnes D (2014) Partner selection in agile supply chains: a fuzzy intelligent approach. Prod Plan Control 25:821-839

Wu C, Barnes D, Rosenberg D, Luo X (2009) An analytic network process-mixed integer multi-objective programming model for partner selection in agile supply chains. Prod Plan Control 20:254-275

Yazdani M, Chatterjee P, Zavadskas EK, Zolfani SH (2017) Integrated QFD-MCDM framework for green supplier selection. J Clean Prod 142:3728-3740

You P, Guo S, Zhao H, Zhao H (2017) Operation performance evaluation of power grid enterprise using a hybrid BWM-TOPSIS method. Sustainability 9:2329

Publisher's note Springer Nature remains neutral with regard to jurisdictional claims in published maps and institutional affiliations. 